\title{
Biliary hitch and ride technique for blind pancreatic duct cannulation
}

Endoscopic pancreatic therapy is indicated in several pancreatic disorders $[1,2]$. Selective pancreatic cannulation can be challenging when pancreatic inflammatory changes are extended to the duodenal wall, as the papilla might be very difficult to identify with the duodenoscope.

We have developed a variation of the "hitch and ride" technique [3], providing blind access to the pancreatic duct in patients with edematous duodenal folds. In this situation, if biliary cannulation is achieved, a guidewire is left in the common bile duct, as described in the double-wire technique [4]. A slitted cannula, as described in the "hitch and ride" technique [3], is used with a second preloaded guidewire. The cannula is hitched on to the biliary guidewire, which can be done in the segment of the guidewire immediately exiting the duodenoscope channel. The cannula is advanced over the guidewire to the location of the ampulla, which is anticipated by the fluoroscopic image, as the edematous folds preclude direct visualization. Once the tip of the cannula is considered by the fluoroscopic image to be slightly enter- ing the papillary orifice, the preloaded guidewire is advanced. If the tip of the cannula is not deeply advanced into the common bile duct, the preloaded guidewire exits the cannula with a perpendicular orientation into the pancreatic duct. If the preloaded guidewire enters the biliary duct, cannulation might be too deep and the cannula must be withdrawn slightly. Several attempts may be needed to achieve pancreatic duct cannulation with the preloaded guidewire.

We present our experiences in two patients ( $\triangleright$ Video 1 ), both 72-year-old women. The first patient had symptomatic pancreatic duct disruption ( $\triangleright$ Fig. 1 ).

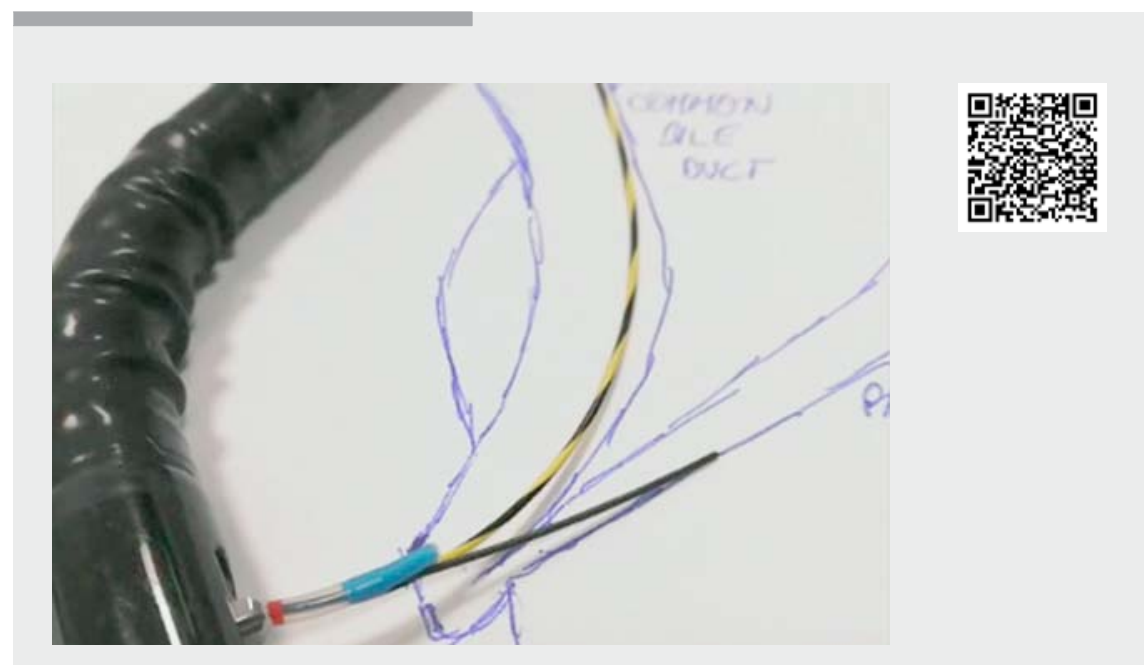

$\square$ Video 1 The "hitch and ride" technique for blind pancreatic cannulation.
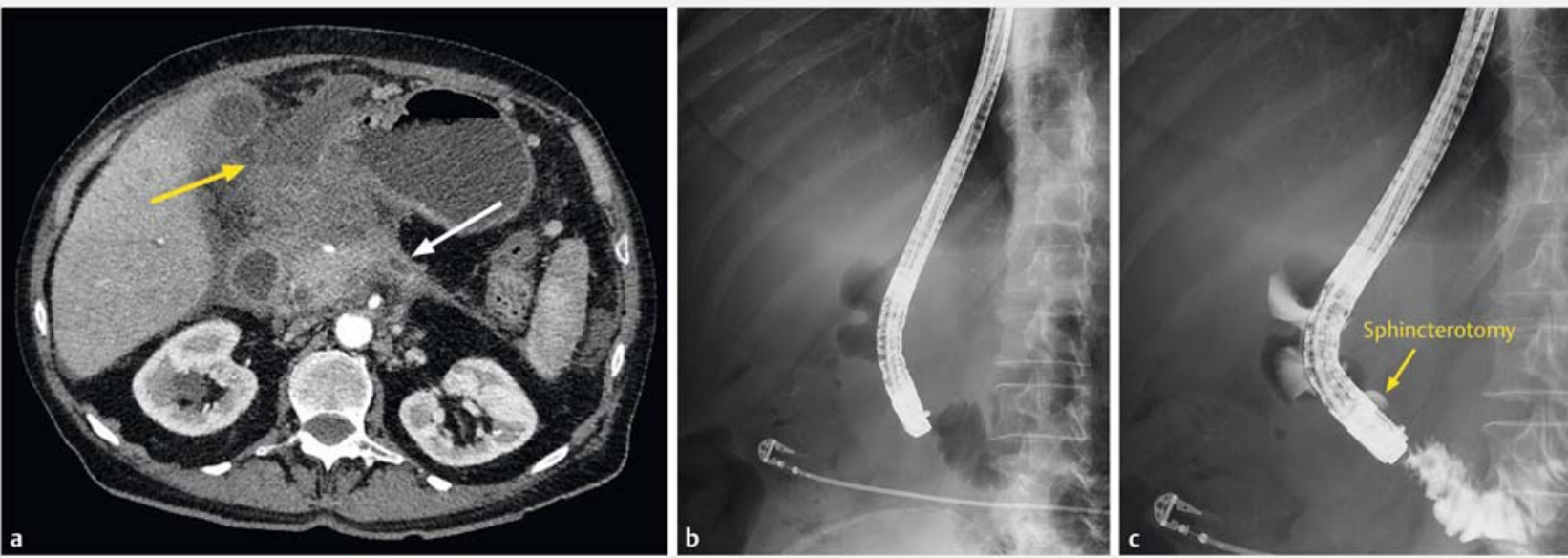

Fig. 1 Patient 1. a This patient experienced recurrent bouts of epigastric pain after a biliary pancreatitis episode. Computed tomography showed new peripancreatic collections (yellow arrow) with mild dilation of the pancreatic duct (white arrow), and therefore pancreatic disruption was suspected. $\mathbf{b}$ Partial stenoses of the second duodenal portion caused by edematous duodenal folds could be seen on fluoroscopy. c Biliary cannulation could be blindly achieved by directing the cannula toward a luminal depression caused by previous biliary sphincterotomy. 

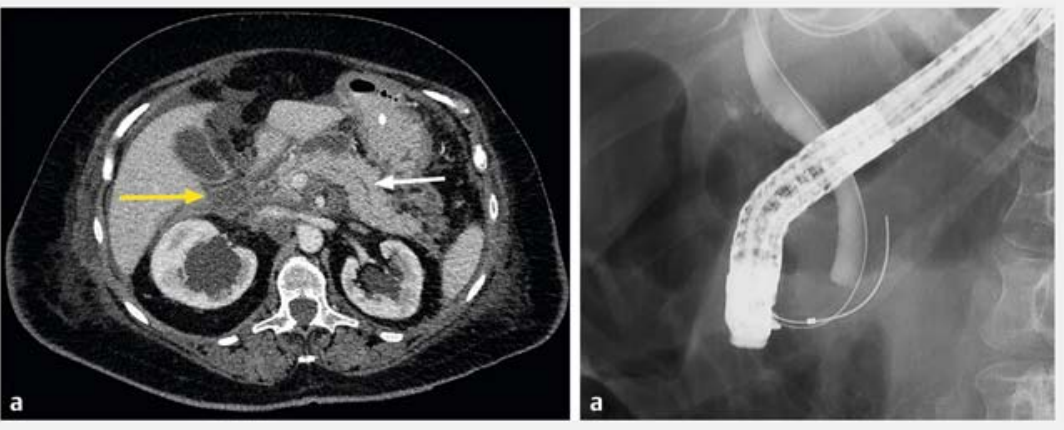

- Fig. 2 Patient 2. a This patient complained of persistent abdominal pain with increased periduodenal inflammatory parameters (yellow arrow), worsening of pancreatic collections, and dilation of the pancreatic duct (white arrow) 4 weeks after an acute pancreatitis episode, consistent with a diagnosis of smoldering pancreatitis. b After biliary cannulation was achieved, the cannula had to be slightly withdrawn and the tip of the scope gently angulated to find the correct alignment with the pancreatic duct.

The second patient had smoldering pancreatitis (> Fig. 2). In both patients, endoscopic retrograde cholangiopancreatography could be completed with clinical success.

Endoscopy_UCTN_Code_TTT_1AR_2AB

Competing interests

Juan J. Vila is consultant for Boston Scientific.

The authors

Juan J. Vila', Juan Carrascosa ${ }^{1}$, Ignacio Fernández-Urién ${ }^{1}$, Paul Yeaton ${ }^{2}$, Gonzalo González ${ }^{1}$, Leire Aburruza ${ }^{1}$, José Manuel Zozaya ${ }^{1}$

1 Endoscopy Unit, Gastroenterology Department, Complejo Hospitalario de Navarra, Pamplona, Spain

2 Endoscopy Unit, Gastroenterology Department, Carilion Clinic, Roanoke, Virginia, United States

\section{Corresponding author}

\section{Juan J. Vila, MD, PhD}

Endoscopy Unit, Gastroenterology Department, Complejo Hospitalario de Navarra, Irunlarrea 3, 31008 Pamplona, Spain

Fax: Fax: +34-848-422303

juanjvila@gmail.com

\section{References}

[1] Reichstein JB, Patel V, Mekaroonkamol P et al. Practice patterns and use of endoscopic retrograde cholangiopancreatography in the management of recurrent acute pancreatitis. Clin Endosc 2020; 53: 73-81

[2] Das R, Yadav D, Papachristou GI. Endoscopic treatment of recurrent acute pancreatitis and smoldering acute pancreatitis. Gastrointest Endosc Clin N Am 2015; 25: 737-748

[3] Nakai Y, Isayama H, Matsubara S et al. A novel "hitch-and-ride" deep biliary cannulation method during rendezvous endoscopic ultrasound-guided ERCP technique. Endoscopy 2017; 49: 983-988

[4] Shamah S, Okolo P. Reverse double-wire cannulation of the pancreatic duct. Clin Gastroenterol Hepatol 2017; 15: 782-783
Bibliography

Endoscopy 2021; 53: E29-E30

DOI 10.1055/a-1173-7910

ISSN 0013-726X

published online 29.5.2020

(c) 2020. Thieme. All rights reserved.

Georg Thieme Verlag KG, Rüdigerstraße 14, 70469 Stuttgart, Germany

\section{ENDOSCOPY E-VIDEOS}

https://eref.thieme.de/e-videos

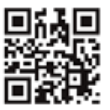

Endoscopy E-Videos is a free access online section, reporting on interesting cases and new techniques in gastroenterological endoscopy. All papers include a high quality video and all contributions are freely accessible online.

This section has its own submission website at https://mc.manuscriptcentral.com/e-videos 